\title{
EDUCAÇÃO, TRABALHO E FLEXIBILIZAÇÃO: PERSPECTIVAS NA AGENDA DAS POLÍTICAS PÚBLICAS NA SOCIEDADE DA INFORMAÇÃO*
}

\author{
WaINe TeIXEIRA JunIOR \\ Universidade Federal de Mato Grosso, Rondonópolis, Mato Grosso, \\ Brasil \\ Sílvia de Fátima Pilegi Rodrigues \\ Universidade Federal de Mato Grosso, Rondonópolis, Mato Grosso, \\ Brasil
}

Resumo: O presente artigo busca apontar os desdobramentos do uso intensivo das novas Tecnologias da Comunicação e da Informação como instrumentos de intensificação de produtividade no modelo neoliberal sob a perspectiva das modificações no campo do trabalho, consequentemente, no perfil do trabalhador e nos caminhos para a sua formação. A elaboração de políticas públicas nesses três segmentos revela-se sob a forma de flexibilização, com consequências importantes para a sociedade. O papel do Banco Mundial é muito relevante nesse contexto, ao revelar em seus documentos diversas recomendações em campos estratégicos estruturais, em especial dentro do domínio da educação, nos países em desenvolvimento. Nesse sentido, é possível observar a forte presença de direcionadores socioeconômicos, tendo em vista a eficiência e a eficácia como metas gerenciais dos processos produtivos. O ensino na modalidade a distância, pelos meios públicos ou privados, pode ocultar aspectos geradores de diferenças e desigualdades.

Palavras-chave: Educação. Trabalho. Políticas Públicas.

MudançAS No tRabalHo E NA FORMAÇÃo do tRABALHADOR

O panorama econômico mundial atual é profundamente influenciado pelas Tecnologias da Informação e Comunicação. Transformações em curso,

* Artigo recebido em 31/10/2012 e aprovado em 15/1/2013. 
desde a década de 1970, combinam a introdução de uso intensivo de tecnologias baseadas em microcomputadores como a robótica e o uso intensivo da Internet como meio de comunicação em todos os segmentos - pessoal, empresarial e governamental - e, por meio dela, a geração de novas oportunidades de negócios. A sociedade contemporânea, compreendida a partir dessa perspectiva, passa a ser denominada Sociedade da Informação. Esse termo passou a ser utilizado também como substituto para o conceito complexo de "sociedade pós-industrial", o "novo paradigma técnico-econômico" (WERTHEIN, 2000, p. 71).

As discussões sobre Sociedade da Informação levam em seu âmago a perspectiva de mudança do paradigma do capital real e concreto para outro tipo de capital virtual e abstrato, que também depende do capital real: o capital informacional e, sobretudo, o conhecimento. Segundo Ferreira (2003, p. 36), no uso desse recurso existe um continuum na forma de uma estrutura circular virtuosa, ou seja, a informação gera conhecimento, e este gera mais informação. Na Sociedade da Informação, espera-se que as pessoas tenham capacidade de gerar e armazenar suas próprias informações, de disseminá-las e ter acesso às informações de terceiros.

Ela traz consigo um conjunto de recursos, além de outros já conhecidos, agora com uma nova roupagem, revestidos de ferramentas e possibilidades de aplicação, grande parte deles realizados particularmente no campo das aplicações das Novas Tecnologias da Comunicação na educação: Educação a Distância, bibliotecas digitais, videoconferência, correio eletrônico, grupos de "bate-papo", voto eletrônico, banco on-line, filmes sob demanda, comércio eletrônico, trabalho a distância. Toda essa gama de novos recursos tecnológicos e seus impactos na sociedade "são gerados fundamentalmente na base produtiva do capitalismo, pautados no fenômeno conhecido como globalização, tendo como objetivo principal a unificação dos mercados" (SCALCON, 2005, p. 111).

Os impactos da Sociedade da Informação, no mundo do trabalho, podem ser observados em um estudo sobre a evolução da economia da informação nos EUA. Segundo Laudon e Laudon (2004, p. 5), desde o início do século XX, os Estados Unidos estão experimentando um aumento significativo da força de trabalho denominada trabalhador do conhecimento, chegando a $60 \%$ de seu efetivo já em 1999. Desse novo trabalhador, por exemplo, exige-se a capacidade permanente de aprendizagem e de adaptação a mudanças, ele deve saber trabalhar em grupo, de preferência em equipes multidisciplinares, e dominar a tecnologia dos computadores. Scalcon (2005) afirma que esse novo perfil de trabalhador também demanda "a possibilidade de realização 
de múltiplas tarefas, preconizando a eficiência e o conhecimento dos mecanismos de produção" (p. 111).

Em meio a transformações estruturais nas relações envolvidas em negócios e meios produtivos, modifica-se a oferta de postos de trabalho, cada vez mais voltados a trabalhadores especializados. Essa modificação, mascarada pela justificativa de crises sequenciais na economia mundial, quase sempre é traduzida em desemprego também mundial. Instaurou-se uma crise das profissões. De acordo com Aranha e Crivellari (2004, p. 45), ela ocorre

em virtude da difusão das novas tecnologias, das novas formas de organização do trabalho, das novas competências, das formas alternativas de relações de emprego que o mundo do trabalho impõe aos trabalhadores. Nesse movimento, ocorre a transformação de antigas atividades ou mesmo o seu desaparecimento. Por outro lado, o surgimento de novas tecnologias ou de novos ramos produtivos pode levar à criação de novas profissões ou ocupações; isto ocorre quando os novos saberes exigidos não correspondem aos perfis profissionais convencionais.

Há 30 anos, a metalurgia, o setor bancário e a administração pública absorviam juntos mais de $80 \%$ da força de trabalho, justamente as três categorias hoje com o maior número de desempregados. Com a revolução tecnológica da Sociedade da Informação, foram colocados computadores ou robôs em montadoras de automóveis e em caixas bancários para serem operados pelos próprios clientes, somando-se a isso, existem políticas neoliberais que conduzem à presença ou participação mínima do governo em todos os setores da sociedade. O setor estatal, por exemplo, responde hoje por pouco mais de $10 \%$ dos postos de trabalho.

$\mathrm{O}$ que fazer com o atual contingente ativo formado na perspectiva de esquemas e estratégias ultrapassadas de produção ou em vias de transformação é questão fundamental de equilíbrio social nessa fase de transição de modelo econômico. Atualmente há apenas políticas compensatórias e de recolocação de desempregados, que se resumem em seguro-desemprego e bolsas de auxílio a famílias carentes. Ações políticas recentes têm propiciado a trabalhadores desempregados sua recolocação no mercado de trabalho, mas o recebimento do seguro-desemprego é condicionado pela matrícula desses profissionais em cursos de requalificação de curta duração (IZAGUIRRE, 2012).

$\mathrm{Na}$ iniciativa privada, encontramos empresários que investem na capacitação de seus trabalhadores. Porém, não há garantia de que esses mesmos trabalhadores continuarão com eles, já que a estratégia de investimento em requalificação tende a ser restrita, pontual e de curto prazo, afirma Coraggio (1996, p. 106). Ainda segundo esse autor, estudos 
apontam que, nesse panorama globalizado, apenas um terço da população vai conseguir integrar-se ao mercado formal de trabalho; uma proporção muito alta ficará desocupada ou vai concorrer entre si, diminuindo ainda mais os salários.

Atualmente há falta de vagas para diversas categorias de trabalho cujas habilidades requeridas demandam conhecimento especializado. Isso faz com que muitos profissionais formados atuem em outras atividades, conforme mostra uma pesquisa do Observatório Universitário sobre a "taxa de aderência", que significa a correspondência entre formação e trabalho para as áreas de conhecimento para os profissionais formados no Brasil (NUNES; MOLHANO, 2006, p. 6). De acordo com esses dados, $53 \%$ dos formandos no país trabalham em setores que não têm relação direta com o curso que fizeram na faculdade. Em meio às piores taxas de aderência, estão os profissionais formados em geografia, cuja categoria conta com apenas $1 \%$ dos formandos trabalhando na área. A pesquisa' aponta também que somente $9,1 \%$ dos formados em ciências econômicas e 9,8\% dos formados em biologia atuam em atividades para as quais foram preparados.

Enquanto várias ocupações sofrem com a escassez de vagas, há outras nas quais a valorização do conhecimento especializado segue em expansão acelerada, como é o caso do setor de Tecnologia da Informação e, mais especificamente, o setor de desenvolvimento de aplicações em software. Segundo dados do Observatório Softex - unidade de estudos e pesquisas da Associação para Promoção da Excelência do Software Brasileiro - Softex (ASSESPRO, 2011), já era prevista a escassez de mão de obra nesse setor, o que poderia fazer com que o Brasil precisasse de 200 mil profissionais em 2013.

\section{A PALAVRA DE ORDEM: FLEXIBILIZAÇÃO}

Passamos por um momento em que nada é previsível. Escolha uma área qualquer da vida, e o que se encontra é incerteza. Seja no que diz respeito à segurança nacional e à vida das empresas, seja no encaminhamento das carreiras individuais. Ninguém mais está seguro de nada. (Tom Peters)

Com essas palavras, o renomado guru corporativo americano Tom Peters (VEJA ON LINE, 2003) afirma que o ritmo de mudanças geradas a partir de crises consecutivas na economia mundial confunde as pessoas e provoca uma ansiedade que pode ser percebida em todos os segmentos da sociedade. E não é para menos. O panorama em que se insere o mundo do trabalho e suas perspectivas aponta um cenário nada animador. Ao buscar a substituição do modelo econômico anterior - o industrial - para o pós-industrial, buscam-se 
mecanismos que sustentem a efetivação da globalização neoliberal com alto grau de sofisticação tecnológica. Scalcon (2005, p. 111) afirma que há

o deslocamento do eixo da rigidez para a flexibilidade, da desqualificação para a qualificação, da fragmentação para a interação. E aqui os meios de comunicação, a informática, a cibernética desempenham papel principal nos processos de transmissão de informações e de interligações dentro de um sistema único.

Nesse sentido, Coraggio (1996, p. 105) afirma que o desenvolvimento da economia"informacional" em oposição à industrial demandará "uma força de trabalho flexível, facilmente reciclável, tanto na esfera individual como na macrossocial". No campo do desenvolvimento pessoal, demanda-se a flexibilidade na adequação do perfil do trabalhador ao mundo do trabalho, ou seja, exige-se a formação multidisciplinar e especialmente a permanente e perpétua formação contínua, mais comumente conhecida como atualização ou capacitação, já que a palavra reciclagem parece ter sido abolida dos jargões da formação profissional para os programas de Qualidade Total. De acordo com Coraggio (1996, p. 87), por recomendação do Banco Mundial,

os trabalhadores da América Latina, desde os níveis de renda mais baixos até os médios, lançados no mercado mundial de trabalho, devem renunciar às leis que os protegiam e competir, simultaneamente, com os trabalhadores mais baratos e mais destituídos de direitos humanos e com os mais capacitados do mundo, que contam com uma infraestrutura de apoio de ponta.

Segundo a Organização Internacional do Trabalho (OIT), existem vários tipos de trabalho flexível: trabalho em tempo parcial, trabalho compartido, horário escalonado, redução da semana de trabalho, horário ajustado e trabalho em turnos. Entretanto, no bojo da modernidade, já é possível encontrar o trabalho e o trabalhador mais flexíveis, ou talvez, já flexibilizados em sua representação máxima no teletrabalho e no teletrabalhador.

A OIT define teletrabalho como a forma de trabalho efetuada em lugar distante do escritório central e/ou do centro de produção, que permita a separação física e que implique o uso de uma nova tecnologia facilitadora da comunicação (HORTA, 2002, p. 2). Em linhas gerais, essa modalidade de atividades profissionais leva o trabalho aos trabalhadores, em vez de levar os trabalhadores ao trabalho.

Em 1997, 11 milhões de teletrabalhadores atuavam na Europa. Já em 1999, os Estados Unidos contavam com 6,7 milhões deles (FETZNER, 2001). Existem vários aspectos que contribuem para o aumento dessa categoria, e diversos estudos realizados em empresas norte--americanas e europeias 
que já instituíram o teletrabalho mostram o aumento significativo da produtividade em valores percentuais. Isso acontece porque, nessa modalidade de atividades, as empresas conseguem planejar e gerir os fluxos de trabalho com maior eficiência, estabelecendo contratos em regime especial (horário flexível, tempo parcial, remuneração por projetos), o que possibilita a diminuição dos custos trabalhistas. Essa vantagem é mais evidente ainda quando o teletrabalhador é um prestador de serviços, pois os tributos da contratação ficam por conta dele.

O Teletrabalhador parece ser o elemento catalisador daquilo que Thomas Friedman (2005) chama de globalização 3.0, no livro $O$ mundo é plano. $O$ autor sugere um mundo plano com o sentido de que a globalização é um processo que busca o nivelamento para que seja possível a competição, ou melhor, que haja "liberalismo igualitário" entre os países industrializados e os países emergentes. Para esse autor, na globalização 1.0, governos e corporações eram os grandes protagonistas; na globalização 2.0, companhias multinacionais conduziam a integração global e, agora, a globalização 3.0 ocorre com o próprio indivíduo. Com o suporte de leis flexibilizadas e tecnologia flexibilizadora, ou seja, que possa suportar modelos de flexibilização de trabalho, pessoas podem, portanto, trabalhar, ou melhor ainda, prestar serviços para empresas em qualquer lugar do mundo sem sair de casa. Sob outro ponto de vista, empresas podem contar com trabalhadores do conhecimento de qualquer lugar do mundo com o uso mínimo de recursos traduzidos em ganho de produtividade e baixos custos.

\section{EDUCAÇÃO A DISTÂNCIA E DEMANDA POR EDUCAÇÃO/FORMAÇÃO}

Historicamente, a Educação a Distância (EaD) surge como uma modalidade de ensino vista, sobretudo, como forma de inclusão daqueles ainda excluídos dos processos educacionais, primordialmente por questões relacionadas à localização de moradia ou de horário, entre outras causas. Regulamentada relativamente há pouco tempo, com frequência a EaD é colocada no centro das discussões na formação de professores. Compreender o eixo principal dessa discussão é importante para afastar "as nuvens" do preconceito e da intolerância.

De fato, não existem estudos que evidenciem ou contestem a efetividade da aprendizagem de acordo com a modalidade na qual ela é oferecida, seja presencial ou a distância. Simonson (2006, p. 49) apresenta, em suas bases teóricas e epistemológicas sobre a $\mathrm{EaD}$, uma série de trabalhos que corroboram essa tese, demonstrando que não há diferença significativa entre a aprendizagem a distância e a aprendizagem presencial; além disso, 
ele afirma que a aprendizagem a distância pode ser considerada tão efetiva quanto a presencial. Quer seja na modalidade exclusivamente a distância ou em formas híbridas com o modelo presencial, a EaD já está estabelecida como modalidade para meios educativos formais ou informais.

Entretanto, como estratégia política para atender à crescente demanda por mais educação, mais alunos e maior carga horária de instrução, a EaD mediada e mediatizada com o uso das Novas Tecnologias da Comunicação e da Informação é altamente atrativa. Em especial, quando se refere a formas e fórmulas que buscam relacionar eficiência, eficácia e custo, a EaD é recomendada repetidamente como recurso para a formação de professores pelo Banco Mundial. Os pontos para o debate começam a ser delineados, portanto, a partir de questões de ordem econômica para além das questões pedagógicas.

Compreendendo o sistema escolar como um conjunto de atividades educativas organizadas com objetivos, tempos, espaços definidos, planejados e geridos como uma organização, é justamente no modelo construído e ofertado pelos sistemas educativos a distância que a intensificação do caráter produtivo acontece. Segundo Torres (1998, p. 140), nas macropropostas políticas mundiais e nacionais, definidas pelo Banco Mundial,

a educação passa a ser analisada com critérios próprios do mercado e a escola é comparada a uma empresa, sendo o ensino resumido a um conjunto de insumos (inputs) que intervêm na caixa preta da sala de aula - o professor sendo mais um insumo e a aprendizagem é vista como o resultado previsível da presença (e eventual combinação) desses insumos.

Seguindo essa perspectiva, todo o processo educativo pode então ser gerido pelo planejamento e pela utilização de insumos e produção de resultados, buscando efetividade em larga escala com baixo custo ou empenho financeiro.

O alemão Otto Peters estudou a EaD como forma industrializada do ensino e aprendizagem, em 1960 (SIMONSON, 2006, p. 49). Para ele, o processo de ensino a distância pode ser analisado como um esquema ou mecanismo de produção industrial e aponta várias características que constituem o alicerce dessa tese: a racionalização e a divisão de trabalho, a mecanização implantada na forma de uso intensivo de tecnologia, linha de montagem, produção em massa, planejamento, organização, métodos de controle científicos, formalização, estandardização, entre outros, que caracterizam plenamente um processo produtivo. Nesse sentido, o estudo e o estudante são cada vez mais vistos como "produtos mercantilizados" (BALL, 2001, p. 108). 
No Brasil, várias têm sido as iniciativas em EaD em cursos de extensão, especialização e graduação, devidamente autorizadas pela legislação (BRASIL, 2007). As Instituições de Ensino Superior (IES) privadas despontaram primeiro para a EaD em um período de grande expansão dessa modalidade, no final dos anos 1990 e início dos anos 2000. Para Giolo (2010, p. 1274), a expansão da EaD, na iniciativa privada, "em essência, consiste numa estratégia de conquista de mercado".

Mais de uma década após a regulamentação da EaD no Brasil, observa-se ainda um crescente número de IES privadas e iniciativas do próprio governo voltando-se ao uso da Internet para ministrar cursos a distância e para ampliar programas educacionais oferecidos em seus campi. Mais recentemente, encontramos também o regime semipresencial, com a implantação de $20 \%$ da carga horária presencial a distância.

Essa expansão, segundo Palloff e Pratt (2002, p. 25), decorre de diversos fatores como, por exemplo, a demanda de um mercado reprimido de alunos impedidos de frequentar cursos presenciais por questões de espaço ou tempo e que, de outra forma, não estudariam; melhoria da qualidade do ensino, pois se pressupõe o uso de novas tecnologias no ensino; uma maneira de satisfazer as necessidades de controle de custos das universidades; e responder à pressão oriunda da competitividade. Observamos, portanto, que os atores econômicos são recorrentes nessas explicações e quase sempre justificadas pela busca de qualidade no ensino, levando consigo a implantação de gerenciamento de produtividade e, consequentemente, de qualidade e custos, num círculo vicioso de eficiência e eficácia.

A redução do custo financeiro na modalidade a distância decorre, dentre outros fatores, de diminuição da infraestrutura, incluindo-se nela a otimização do corpo docente; do estabelecimento de parcerias com outras instituições estruturadas para o ensino presencial, para a realização de encontros não presenciais, que já são em pequeno número, assim, não é necessário investir em construção de prédios, montar laboratórios ou adquirir equipamentos para equipar salas. Podemos ainda adicionar a tudo isso os custos de manutenção, segurança, energia elétrica e mão de obra.

Vale ressaltar que, com a redução do corpo docente, na maioria das vezes, há redução também da qualificação profissional. Contratam-se poucos especialistas qualificados para a produção de material didático e muitos professores com menor qualificação, reduzidos à categoria de tutores, com baixos salários, para atender milhares de alunos.

Ao observarmos os dados do Censo da Educação Superior de 2010 realizado pelo Instituto Nacional de Estudos e Pesquisas Educacionais Anísio 
Teixeira (INEP), observamos que o número total das vagas na EaD chega a 930 mil matrículas, sendo que a rede privada é responsável pela oferta de 80,5\% do total (EDUCAÇÃO, 2012a). Portanto, existe uma grande demanda por vagas que não são suficientemente ofertadas pelo serviço público; é natural que os alunos busquem oportunidades em estudos na iniciativa privada. Dessa forma, infelizmente, o custo pesa mais que a qualidade, na maioria das vezes. Verifica-se que há a exigência de um mercado, ou melhor, de um público de estudantes por cursar o ensino superior, reprimido ainda por diversos fatores, mas talvez o fator econômico seja um dos mais significativos.

Na formação pela modalidade a distância, há ainda outra grande demanda a ser considerada: a necessidade de formação de professores. Existe um alto contingente de professores sem formação adequada trabalhando em lugares tradicionalmente esquecidos pelas políticas públicas e pelo desenvolvimento econômico. Quase 354 mil professores que lecionam na rede pública da educação básica, nos anos finais do ensino fundamental e nos três anos do ensino médio, não têm formação específica na disciplina em que atuam (CNTE, 2012). Vale lembrar que, em virtude desse atendimento formativo, foram realizados pelo Estado os primeiros movimentos para implantar redes de educação a distância (GIOLO, 2010, p. 1274).

A rede privada de ensino, desde que devidamente autorizada pelos meios reguladores do Governo, também privilegiou exatamente a área de formação de professores, especialmente a Pedagogia - curso com mais estudantes em graduações a distância no Brasil. Entre os trinta cursos mais procurados na EaD, a Pedagogia correspondia a 119.298 das 273 mil matrículas efetuadas, a maior parte delas no segmento privado (239.679) e em menor parte no segmento público (33.569), segundo o Censo da Educação Superior de 2010 (EDUCAÇÃO, 2012b). ${ }^{2}$

Nos cursos a distância oferecidos pelo segmento público, as vagas tendem a aumentar. Segundo o diretor de Educação a Distância da Capes (Coordenação de Aperfeiçoamento de Pessoal de Nível Superior), João Carlos Teatini, responsável pelo programa Universidade Aberta do Brasil (UAB), o Ministério da Educação (MEC) pretende triplicar o número de matrículas em cursos públicos de EaD para 600 mil até este ano (2014). Vale destacar que, segundo esse pronunciamento, ainda há vários obstáculos, os maiores são o preconceito e a resistência à modalidade e as dificuldades de conexão, além da falta de banda larga pelo país (EDUCAÇÃO, 2012a). 


\section{A FLEXIBILIZAÇ̃̃O DO ENSINO}

Ao afirmar que "a aprendizagem precisa se tornar mais flexível e diferenciada para permitir mecanismos de distribuição (delivery) alternativos" (WORLD BANK, 2003, p. 65 apud BARRETO, 2010, p. 427), é possível compreender porque as práticas de flexibilização constam também na agenda das políticas voltadas ao segmento da educação.

Um fato curioso diz respeito a questões de estratégia de atuação da própria $U A B$, a começar pelo termo Universidade Aberta do Brasil, e não outro tal como Universidade de Educação a Distância do Brasil, por exemplo. Verificamos, todavia, que o termo abertura encontra-se em completo alinhamento com as diretrizes de flexibilização. García Aretio (2006), ao definir o conceito de Aprendizagem Aberta, afirma:

A aprendizagem aberta se refere a estudos em um ambiente de aprendizagem flexível, formal ou informal, onde o estudante tem a liberdade de escolher e a oportunidade de determinar as metas de sua aprendizagem, e de resolver as questões relativas ao tempo e lugar do estudo além daquelas programadas. O estudante deve ter a oportunidade de controlar seus estudos e de receber retroalimentação na forma que ele deseja. (p. 15)

Para Santos (2008, p. 290), o conceito de abertura em universidades e sistemas abertos de aprendizagem varia imensamente. A indicação de quão aberta é uma universidade está nas restrições (ou na falta delas). Segundo García Aretio (2006, p. 13), esse conceito foi inicialmente criado na Inglaterra com a Open University, definindo como características a entrada a qualquer tempo, sem processo seletivo nem vestibular; a ausência de campus universitário; a utilização de todos os meios de comunicação para educar (métodos livres e variados modos de aprender); a aquisição de competências e experiências necessárias para a aprendizagem (ideias livres, acesso a diversas teorias e doutrinas livres).

Em nosso país, em virtude das exigências da legislação do ensino superior, a Universidade Aberta do Brasil ainda é uma universidade com restrições adaptadas à questão da palavra abertura. Existem requisitos e exames de ingresso (vestibular) para os cursos de graduação e processo seletivo para a maioria dos cursos de pós-graduação, usualmente os alunos têm de se adequar a propostas pedagógicas "fechadas", que restringem as possibilidades de escolha e autonomia da gestão pessoal do curso realizado.

Mas não é só na modalidade a distância que a flexibilização acontece na educação. Discussões e ações recentes de propostas denominadas estruturas curriculares inovadoras e ciclos básicos de formação profissional podem se revelar como possibilidades atraentes de modelos pedagógicos 
de formação; no entanto, podem funcionar facilmente como estratégias de eliminação de custos de infraestrutura, incluindo-se nelas também a redução de mão de obra docente. Na recém-criada Universidade Federal do $A B C$ (UFABC), de São Paulo, o ciclo básico já é realidade e aparece de forma recorrente em discussões, fóruns e pautas de reitores, com a possibilidade de adaptação e implantação em outras universidades.

\section{CONSIDERAÇÕES FINAIS}

O desenvolvimento acelerado das Tecnologias da Informação e da Comunicação tem provocado diversas mudanças nos meios produtivos e no mundo do trabalho; por consequência, em quase todos os segmentos da sociedade. Um processo de mudança comportamental está em curso.

Para atingir o perfil desejado para cidadãos de uma nova ordem informacional, necessita-se de habilidades e competências que o sistema educacional formal pode ainda não estar devidamente preparado. Parece que a resposta à pergunta Para que formar pessoas na Sociedade da Informação? já está dada antes mesmo de a questão ser formulada, restando apenas aos legisladores das políticas para o ensino planejarem "como" fazer isso. Afinal de contas, segundo uma recomendação do Banco Mundial, "para que um país seja competitivo e possa atrair capitais para a produção de bens e serviços exportáveis, recomenda-se a oferta de força de trabalho tecnicamente flexível" (CORAGGIO, 1996, p. 80).

No campo do mercado do trabalho, precisa-se de flexibilidade em diversos níveis: estrutura organizacional, recursos infraestruturais e regulamentação trabalhista. Leis trabalhistas rígidas e classificadas como "ultrapassadas" pelos proponentes de novas políticas, com a finalidade de otimização do setor produtivo, precisam ser revistas e reformuladas para atender à demanda produtiva. Entretanto, os esforços para flexibilizar as leis trabalhistas nos últimos anos, na busca por atender as necessidades dos trabalhadores e as possibilidades do empregador, não foram capazes de reduzir o desemprego no Brasil. Estudos já comprovaram que, ao proteger cada vez menos os trabalhadores, as leis trabalhistas provocam a busca pela economia informal por grande parte da parcela da mão de obra produtiva do país (MATIAS-PEREIRA, 2009, p. 30). O desafio é promover o crescimento econômico baseado em tecnologias de trabalho intensivo, visto que o modelo de sociedade informacional é também o eliminador de força de trabalho.

Se a EaD é realidade no processo de democratização do ensino, então, é preciso melhorar as condições de sua efetivação com a mesma qualidade com que lutamos para o ensino presencial. Uma vez que a proposta 
flexibilizadora é colocada tanto na perspectiva dos ajustes curriculares do ensino presencial quanto na $\mathrm{EaD}$, é preciso promover caminhos para que a sua efetivação não oculte nela situações de desigualdades entre instituições, modalidades, currículos e, especialmente, alunos.

\section{EDUCATION, WORK AND FLEXIBILIZATION: PERSPECTIVES ON THE PUBLIC POLICY AGENDA IN THE INFORMATION SOCIETY}

ABSTRACT: This article sets out to identify the developments involved in the intensive use of new technologies of communication and information as tools for productivity enhancement in the neoliberal model from the perspective of changes in the field of labor and, consequently, in the profile of workers and paths for their formation. The drawing up of policies in these three segments is seen under the form of aspects of flexibility, with far-reaching consequences for society. The role of the World Bank is highly relevant in this context, as its documents present various recommendations for strategic structural fields, especially within that of education in developing countries. In this context, a strong presence of socioeconomic guidelines can be seen, with a focus on efficiency and effectiveness as the management goals of production processes. Distance education, whether in public or private institutions, could be hiding aspects which generate differences and inequalities.

KEY WORDS: Education. Work. Public policies.

\section{EDUCACIÓN, TRABAJO Y FLEXIBILIZACIÓN: PERSPECTIVAS EN LA AGENDA DE LAS POLÍTICAS PÚBLICAS EN LA SOCIEDAD DE LA INFORMACIÓN}

RESUMEN: El presente artículo busca señalar los desdoblamientos del uso intensivo de las nuevas Tecnologías de la Comunicación y de la Información como instrumentos de intensificación de la productividad en el modelo neoliberal, bajo la perspectiva de las modificaciones en el campo del trabajo, por consiguiente, en el perfil del trabajador y en los caminos para su formación. La elaboración de políticas públicas en esos tres segmentos se revela bajo la forma de aspectos de flexibilización, con consecuencias importantes para la sociedad. El papel del Banco Mundial es altamente relevante dentro de ese contexto, al revelar en sus documentos diversas recomendaciones en campos estratégicos estructurales, principalmente dentro del dominio de la educación en los países en desarrollo. En este contexto, es posible observar la fuerte presencia de orientadores socioeconómicos visando a la eficiencia y la eficacia como metas gerenciales de los procesos productivos. La enseñanza bajo la modalidad a distancia, ya sea por los medios públicos o privados, puede ocultar aspectos generadores de diferencias y desigualdades.

Palabras Claves: Educación. Trabajo. Políticas públicas. 


\section{NOTAS}

1. Sobre as categorias mais conhecidas, as pesquisas apontam os seguintes números: Pedagogia com 56,2\%, Letras com 54,7\%, Direito com 51,3\%, Administração com $46,4 \%$ e Contábeis com 39,8\%.

2. São elas: Pedagogia - 273.248; Formação de professor de língua/literatura vernácula (português) - 28.591; Formação de professor de matemática - 23.328; Formação de professor de biologia - 19.087; Formação de professor de história - 17.919; Formação de professor de língua/literatura estrangeira moderna - 14.654; Formação de professor de geografia - 9.495; Formação de professor de língua/literatura vernácula e língua estrangeira moderna - 6.876; Formação de professor de física - 5.871; Formação de professor de química - 4.309; Formação de professor de Artes Visuais - 3.663 (EDUCAÇÃO UOL, 2012b).

\section{REFERÊNCIAS}

ARANHA, A. V. S.; CRIVELLARI, H. M. T. Formação e ocupação profissional no modelo de competência: maior inclusão social? Revista de Administração FEAD, v. 1, n. 2, 2004. Disponível em: <http://revista.fead.br/index.php/adm/article/download/77/56>. Acesso em: 5 jul. 2012.

ASSESPRO. Escassez de profissionais de TI pode chegar a 200 mil em 2013. Softex corre contra o tempo com programas de qualificação para a área e os resultados são positivos. 2011. Disponível em: <http://empauta.assespro-mg.org.br/?p=5254>. Acesso em: 5 jul. 2012.

BALL, S. J. Diretrizes políticas globais e relações políticas locais em educação. Currículo sem fronteiras, Porto Alegre, v. 1, n. 2, p. 24-43, 2001.

BARRETO, R. G. Configuração da política nacional de formação de professores a distância. Em Aberto, Brasília, v. 23, n. 84, p. 33-45, nov. 2010. Disponível em: <http://emaberto. inep.gov.br/index.php/emaberto/article/viewFile/1789/1352 >. Acesso em: 5 jul. 2012.

BRASIL, Secretaria de Educação a Distância -SEED/MEC. Regulamentação da educação a distância no Brasil. Disponível em: <http://portal.mec.gov.br/index.php?option=com_ content\&id=12778\%3Alegislacao-de-educacao-a-distancia\&ltemid=865>. Acesso em: 5 jul. 2012.

CNTE. Faltam professores para o ensino básico e médio. Disponível em: <http://www. cnte.org.br/index.php/comunica\%C3\%A7\%C3\%A3o/noticias/987-faltam-professores-para-o-ensino-basico-e-medio>. Acesso em: 5 jul. 2012.

CORAGGIO, J. L. Propostas do Banco Mundial para a educação: sentido oculto ou problemas de concepção? In: TOMMASI, L. De; WARDE, J. M.; HADDAD, S. (Orgs.). O Banco Mundial e as políticas educacionais. São Paulo: Cortez/Ação Educativa/PUC-SP, 1996. p. 75-124. 
EDUCAÇÃO. UOL. MEC promete triplicar matrículas em EAD e alcançar 600 mil alunos até 2014. Disponível em: <http://educacao.uol.com.br/noticias/2012/04/24/mec-promete-triplicar-matriculas-em-ead-ate-2014-e-alcancar-600-mil-alunos.htm >. Acesso em: 5 jul. 2012a.

EDUCAÇÃO. UOL. Pedagogia é o curso de graduação a distância mais procurado do Brasil. Disponível em: <http://educacao.uol.com.br/noticias/2012/05/30/pedagogiae-o-curso-de-graduacao-a-distancia-mais-procurado-do-brasil-veja-a-lista.htm $>$. Acesso em: 5 jul. 2012b.

FERREIRA, R. da S. A sociedade da informação no Brasil: um ensaio sobre os desafios do Estado. Ci. Inf., Brasília, v. 32, n. 1, abr., 2003. Disponível em: <http://www.scielo. $\mathrm{br} /$ scielo.php?script=sci_arttext\&pid=S0100-19652003000100004\&lng=en\&nrm=i so>. Acesso em: 5 jul. 2012.

FETZNER, M. A. de M. A viabilidade do teletrabalho na PROCEMPRA. Read. Revista Eletrônica de Administração, Porto Alegre, on line, v. 7, p. 2-28, 2001. Disponível em: <http:// www.seer.ufrgs.br/index.php/read/article/view/15708>. Acesso em: 29 jul. 2010.

FRIEDMAN, T. O mundo é plano: uma breve história do século XXI. São Paulo: Objetiva, 2005.

GARCÍA ARETIO, L. La educación a distancia: de la teoría a la práctica. 3. ed. Barcelona: Ariel, 2006.

GIOLO, J. Educação a distância: tensões entre o público e o privado. Educação e Sociedade, Campinas, v. 31, n. 113, p. 1271-1298, out./dez., 2010.

HORTA, E. B. A introdução teletrabalho na sociedade contemporânea com a utilização das ferramentas de comunicação. INTERCOM - Sociedade Brasileira de Estudos Interdisciplinares da Comunicação. XXV Congresso Brasileiro de Ciências da Comunicação - Salvador/BA - 1 a 5 de setembro. 2002. 1 Trabalho apresentado no NP08 - Núcleo de Pesquisa Tecnologias da Informação e da Comunicação, XXV Congresso Anual em Ciência da Comunicação, Salvador/BA, 04 e 05 de setembro. 2002. Disponível em: < http:// www.intercom.org.br/papers/nacionais/2002/Congresso2002_Anais/2002_NP8DIAS. pdf>. Acesso em: 5 jul. 2012.

IZAGUIRRE, M. Governo regulamenta exigência de curso para receber seguro-desemprego. Disponível em: < http://economia.uol.com.br/ultimas-noticias/valor/2012/04/17/ governo-regulamenta-exigencia-de-curso-para-receber-seguro-desemprego.jhtm $>$. Acesso em: 5 jul. 2012.

LAUDON, K. C.; LAUDON, J. P. Sistemas de informação gerenciais. 5. ed. São Paulo: Person Brasil, 2004.

MATIAS-PEREIRA, J. Crise financeira global, políticas públicas de geração de emprego e flexibilização da legislação trabalhista no Brasil. Revista de Economia Política e História Econômica, n. 18, agosto de 2009. Disponível em: <http://repositorio.bce.unb.br/ bitstream/10482/3676/1/ARTIGO_CriseFinanceiraGlobal.pdf>. Acesso em: 5 jul. 2012. 
NUNES, E.; MOLHANO, L. A reforma que não houve. Documento de Trabalho n. 53. 2006. Disponível em: <http://www.databrasil.org.br/pdf_docs/Doctrab53.pdf>. Acesso em: 5 jul. 2012.

PALLOFF, R. M.; PRATT, K. Construindo comunidades de aprendizagem no ciberespaço. Estratégias eficientes para a sala de aula on-line. Porto Alegre: Artmed, 2002.

VEJA ON-LINE. PETERS, T. O mundo está um caos. Entrevista. 17/12/2003. Entrevista concedida a Tânia Menai. Disponível em: <http://veja.abril.com.br/171203/entrevista. html>. Acesso em: 5 jul. 2012.

SANTOS, A. I. O conceito de abertura em EAD. In: LITTO, F. M.; FORMIGA, M. (Orgs.). Educação a distância. São Paulo: Pearson, 2008.

SCALCON, S. Formação: o viés das políticas de (trans) formação docente para o século XXI. In: ALMEIDA, M. (Org.). Políticas educacionais e práticas pedagógicas: para além da mercadorização do conhecimento. Campinas: Alínea, 2005, v. 1. p. 105-125.

SILVA, A. et al. Estudo do teletrabalho em Portugal. FUNDETEC/IEFP, 1999. Disponível em: <http://www.dlt.pt/_teletrabalho1.asp>. Acesso em: 5 jul. 2012.

SIMONSON, M. Teoría, investigación y educación a distancia. In: BARBERÀ, E. et al. Educación abierta y a distancia. Barcelona: Editorial UOC, 2006.

TORRES, R. M. Melhorar a qualidade da educação básica? As estratégias do Banco Mundial. In: TOMMASI, L.; WARDE, M. J.; HADDAD, S. (Orgs.). O Banco Mundial e as políticas educacionais. 2. ed. São Paulo: Cortez, 1998. p. 125-193.

WERTHEIN, J. A sociedade da informação e seus desafios. Ci. Inf., Brasília, v. 29, n. 2, ago 2000. Disponível em: <http://www.scielo.br/scielo.php?script=sci_arttext\&pid=S0100$-19652000000200009 \& \operatorname{lng}=p t \& n r m=i s o$ > . Acesso em: 5 jul. 2012.

WaINe TeIXEIRA JunIOR é bacharel em Ciência da Computação pelas Faculdades Integradas Riopretense, especialista em Design Instrucional para EAD Virtual pela Universidade Federal de Itajubá, mestre em Ciência da Computação pelo Instituto de Ciências Matemáticas e Computação, USP de São Carlos, e doutorando em Recursos Naturais pela Universidade Federal de Campina Grande. Atualmente é professor assistente do Curso de Sistemas de Informação da Universidade Federal de Mato Grosso/UFMT, Campus Universitário de Rondonópolis. Tem experiência na área de Computação e Educação a Distância, atuando sobretudo nos seguintes temas: Design Instrucional para $E_{a} D$, formação docente, ensino de linguagem de programação, inclusão digital, geotecnologias.

E-mail:waine.jr@smail.com 